\title{
Evidence for antimicrobial activity associated with common house spider silk
}

\author{
Simon Wright ${ }^{*}$ and Sara L Goodacre
}

\begin{abstract}
Background: Spider silk is one of the most versatile materials in nature with great strength and flexibility. Native and synthetically produced silk has been used in a wide range of applications including the construction of artificial tendons and as substrates for human cell growth. In the literature there are anecdotal reports that suggest that native spider silk may also have antimicrobial properties.

Findings: In this study we compared the growth of a Gram positive and a Gram negative bacterium in the presence and absence of silk produced by the common house spider Tegenaria domestica. We demonstrate that native web silk of Tegenaria domestica can inhibit the growth of the Gram positive bacterium, Bacillus subtilis. No significant inhibition of growth was detected against the Gram negative bacterium, Escherichia coli. The antimicrobial effect against $B$. subtilis appears to be short lived thus the active agent potentially acts in a bacteriostatic rather than bactericidal manner. Treatment of the silk with Proteinase $\mathrm{K}$ appears to reduce the ability to inhibit bacterial growth. This is consistent with the active agent including a protein element that is denatured or cleaved by treatment. Tegenaria silk does not appear to inhibit the growth of mammalian cells in vitro thus there is the potential for therapeutic applications.
\end{abstract}

Keywords: Spider, Silk, Antimicrobial, Antibacterial, Bacillus subtilis, Escherichia coli, Tegenaria domestica

\section{Background}

Spiders use silk for a variety of different purposes such as web spinning, cocoon construction and as substrates upon which to deposit sperm. Silks vary in their mechanical properties such as in the degree of extensibility and maximum strength [1] [2]. The range of physical properties observed likely reflects differences amongst silk types in the relative proportions and combinations of particular amino acids such as alanine, glycine and proline [3].

Spider silks can be grouped into five basic categories: dragline (also known as major ampullate), capture spiral, tubiliform, aciniform and minor-ampullate silks, each of which is used for a different purpose. In this study we examined the properties of combined samples of dragline and capture spiral silk from the agelenid spider Tegenaria domestica (Clerk 1757). This spider weaves funnel webs and is commonly found in leaf detritus or underneath rocks [4]. It uses dragline silk for creating the web's outer rim and spokes, and also for the lifeline that

* Correspondence: simonjwright8800@aol.com

School of Biologoy, University of Nottingham, University Park, NG7 2RD, Nottingham, UK attaches the spider to a surface. Capture spiral silk is used for the capture lines on the web. As its name suggests, it is used for capturing prey as they collide with the web. In order to do this it stretches so as to prevent breakage by absorbing the impact energy. Capture spiral silk is also sticky. Glycoproteins covering the surface are important in determining both the stickiness and stretchiness of the silk [5].

There are records indicating that spider silk has historically been used by humans for a variety of purposes. Peoples of the Carpathian Mountains are reported as using sections of the tubular shaped webs of Atypus spiders as topical bandages to heal wounds. This was believed to be beneficial due to the antiseptic properties of the spider silk [6]. Few studies, however, appear to have investigated this property in detail. In this study we challenged two types of bacterial cultures, Gram negative E. coli and Gram positive B. subtilis, with naturally spun spider silk using an in vitro assay. We examined the growth response of bacteria to native silk and to silk that had been chemically treated in order to investigate what the active antimicrobial agent might be. We also exposed
C Biomed Central

(c) 2012 Wright and Goodacre; licensee BioMed Central Ltd. This is an Open Access article distributed under the terms of the Creative Commons Attribution License (http://creativecommons.org/licenses/by/2.0), which permits unrestricted use,

distribution, and reproduction in any medium, provided the original work is properly cited. 
mammalian cell cultures to natural spider silk in order to examine whether silk appears to be tolerated by these types of cell, a factor that is important in assessing the potential for subsequent therapeutic applications in the treatment of human disease.

\section{Methods}

\section{Tests for antimicrobial activity}

To test for antimicrobial activity of spider silk we incubated bacterial cultures in the presence and absence of silk and measured bacterial growth using photospectrometry. $10 \mathrm{ml}$ of liquid Luria broth in a sterile $20 \mathrm{ml}$ universal tube was inoculated with $50 \mu$ l overnight culture of either E. coli or B. subtilis. Silk was collected by running a sterile pipette through the web to collect a sheet of approximately $7 \mathrm{~mm}^{2}$. Both the silk and the sterile pipette with which the silk was collected were submerged in the mix of the liquid broth and microbe. The tubes were placed on a shaker rotating at $150 \mathrm{rpm}$ and heated to $27^{\circ} \mathrm{C}$. After incubation, $2 \mathrm{mls}$ of the sample was pipetted into a cuvette which was placed in a photo-spectrometer (Biochrom Libra S6) and the absorbance read at $660 \mathrm{~nm}$. Light absorbance is expected to be proportional to bacterial density in the medium with absorbance increasing with microbial density. All silk samples were incubated for 24 hours with a subset incubated for a further 24 hours. A series of tests using freshly spun silk from a single UK Tegenaria male were carried out over the space of a few weeks. Each experimental culture containing silk was paired with a control culture inoculated at the same time with bacteria but no silk.

Statistical analyses of light absorbance data were made using both the sign test and the paired samples t-test. The a priori prediction that silk reduces growth was used and thus the results are reported as 1-tailed.

To further characterise the active agents on the spider silk that inhibit the growth of microbes, silk was subjected to a range of different treatments; (i) exposing to ultraviolet light $(254 \mathrm{~nm})$ for 20 minutes; (ii) soaking in sterile distilled water for 1-2 hours before use and (iii) incubating with Proteinase K for 1-2 hours before use. Soaking in Proteinase $\mathrm{K}$ was used to establish whether the agent was behaving as if it was a protein $i$. e. being destroyed or denatured under the conditions applied. Exposure to UV light at $254 \mathrm{~nm}$ is expected to damage DNA and thus affect microorganisms that are already present on the silk sample, but not necessarily to denature proteins. Soaking in water was used to see if any active agent was present on the silk surface and soluble.

\section{Mammalian cell line}

The effects of spider silk on mammalian cell lines were investigated by incubating silk with Jurkat cells. Jurkat cells were removed from liquid nitrogen storage and thawed in a water bath at $37^{\circ} \mathrm{C}$. After heating for around 10 minutes, approximately $3 \times 10^{5}$ cells were added to $5 \mathrm{ml}$ of mammalian cell growth medium and incubated at $37^{\circ} \mathrm{C}$ in the presence of $5 \% \mathrm{CO}_{2}$. They were then left to grow for two days, during which time the $\mathrm{pH}$ of the culture was measured daily, before being removed and the number of cells calculated by taking $20 \mu \mathrm{l}$ of cell suspension, staining cells with an equal volume of Trypan Blue dye and counting the number of cells using a haemocytometer.

Mammalian cells are highly susceptible to bacterial infections therefore the spider silk used was subjected to 20 minutes of UV irradiation before the experiment by placing for 20 minutes beneath a UV source in a laminar flow hood ( $254 \mathrm{~nm}, 15$ watts). Exposure at this wavelength is expected to reduce or eliminate any bacteria that are present on the silk and had been shown by preliminary trials not to eliminate the antimicrobial activity of the silk.

\section{Results}

\section{Tests for antimicrobial activity}

A total of 18 paired trials were carried out testing the effect of $T$. domestica silk on B. subtilis growth (Table 1). After 24 hours a significant proportion of trials (14/18) showed less B. subtilis growth when in the presence of Tegenaria silk (mean absorbance: B. subtilis alone $=0.76$,

Table 1 Table of absorbance readings of growth of $B$. subtilis when exposed to the silk of $T$. domestica

\begin{tabular}{|c|c|c|c|c|}
\hline Trial No. & $\begin{array}{l}\text { Control } \\
\text { absorbance } \\
\text { reading }\end{array}$ & $\begin{array}{l}\text { Silk sample } \\
\text { reading }\end{array}$ & Inhibition \% & Sign test \\
\hline 1 & 0.34 & 0.315 & 7.352941 & + \\
\hline 2 & 0.34 & 0.28 & 17.64706 & + \\
\hline 3 & 0.32 & 0.28 & 12.5 & + \\
\hline 4 & 0.57 & 0.54 & 5.263158 & + \\
\hline 5 & 0.5 & 0.54 & -8 & - \\
\hline 6 & 0.585 & 0.582 & 0.512821 & + \\
\hline 7 & 0.575 & 0.57 & 0.869565 & + \\
\hline 8 & 0.63 & 0.44 & 30.15873 & + \\
\hline 9 & 1.22 & 0.57 & 53.27869 & + \\
\hline 10 & 1.29 & 0.42 & 67.44186 & + \\
\hline 11 & 0.61 & 0.56 & 8.196721 & + \\
\hline 12 & 0.58 & 0.53 & 8.62069 & + \\
\hline 13 & 0.6 & 0.5 & 16.66667 & + \\
\hline 14 & 0.71 & 0.77 & -8.4507 & - \\
\hline 15 & 0.64 & 0.55 & 14.0625 & + \\
\hline 16 & 1.03 & 1.06 & -2.91262 & - \\
\hline 17 & 0.95 & 0.96 & -1.05263 & - \\
\hline 18 & 2.1 & 2 & 4.761905 & + \\
\hline
\end{tabular}


Table 2 Table of absorbance readings of growth of E.coli when exposed to the silk of $T$. domestica

\begin{tabular}{|c|c|c|c|c|}
\hline Trial No. & $\begin{array}{l}\text { Control } \\
\text { absorbance } \\
\text { reading }\end{array}$ & $\begin{array}{l}\text { Silk sample } \\
\text { reading }\end{array}$ & Inhibition \% & Sign test \\
\hline 1 & 0.06 & 0.055 & 8.333333 & + \\
\hline 2 & 0.15 & 0.07 & 53.33333 & + \\
\hline 3 & 0.11 & 0.065 & 40.90909 & + \\
\hline 4 & 0.13 & 0.08 & 38.46154 & + \\
\hline 5 & 0.15 & 0.11 & 26.66667 & + \\
\hline 6 & 0.07 & 0.065 & 7.142857 & + \\
\hline 7 & 0.33 & 0.33 & 0 & \\
\hline 8 & 0.43 & 0.4 & 6.976744 & + \\
\hline 9 & 1.244 & 1.22 & 1.92926 & + \\
\hline 10 & 0.33 & 0.35 & -6.06061 & - \\
\hline 11 & 0.33 & 0.33 & 0 & \\
\hline 12 & 1.244 & 1.15 & 7.55627 & + \\
\hline 13 & 1.244 & 1.19 & 4.340836 & + \\
\hline 14 & 1.25 & 1.21 & 3.2 & + \\
\hline 15 & 0.74 & 0.77 & -4.05405 & - \\
\hline 16 & 1.08 & 1.03 & 4.62963 & + \\
\hline 17 & 0.88 & 1.15 & -30.6818 & - \\
\hline 18 & 0.76 & 1.26 & -65.7895 & - \\
\hline 19 & 0.89 & 1.18 & -32.5843 & - \\
\hline 20 & 0.94 & 1 & -6.38298 & - \\
\hline 21 & 0.58 & 0.57 & 1.724138 & + \\
\hline 22 & 1.03 & 1.01 & 1.941748 & + \\
\hline 23 & 2.5 & 2.5 & 0 & \\
\hline 24 & 2.41 & 2.42 & -0.41494 & - \\
\hline 25 & 2.5 & 2.45 & 2 & + \\
\hline
\end{tabular}

B. subtilis plus silk $=0.64$, sign test $+14,-4, P=0.015$ ). Paired samples t-tests, which take the magnitude of the difference between silk and control samples into account also support the conclusion that bacterial growth is less when in the presence of silk $(t=2.052,17$ d.f., $P=0.028)$.

Table 3 Table of absorbance readings of growth of $B$. subtilis when exposed to the ultraviolet-light treated silk of $T$. domestica

\begin{tabular}{lllcc}
\hline Trial No. & $\begin{array}{l}\text { Control } \\
\text { absorbance } \\
\text { reading }\end{array}$ & $\begin{array}{l}\text { Silk sample } \\
\text { reading }\end{array}$ & Inhibition \% & Sign test \\
\hline 1 & 0.32 & 0.26 & 18.75 & + \\
2 & 0.54 & 0.53 & .93 & + \\
3 & 0.39 & 0.37 & 5.13 & + \\
4 & 0.58 & 0.55 & 5.17 & + \\
5 & 0.71 & 0.68 & 4.23 & + \\
\hline
\end{tabular}

Table 4 Table of absorbance readings of growth of B. subtilis when exposed to the water soaked silk of T. domestica

\begin{tabular}{lllcc}
\hline Trial No. & $\begin{array}{l}\text { Control } \\
\text { absorbance } \\
\text { reading }\end{array}$ & $\begin{array}{l}\text { Silk sample } \\
\text { reading }\end{array}$ & Inhibition \% & Sign test \\
\hline 1 & 0.61 & 0.55 & 9.84 & + \\
2 & 0.54 & 1.00 & -86.92 & - \\
3 & 0.71 & 0.65 & 8.45 & + \\
4 & 1.10 & 1.06 & 3.64 & + \\
5 & 0.42 & 0.53 & -26.19 & - \\
6 & 0.42 & 0.49 & -16.67 & - \\
7 & 0.49 & 0.51 & -4.08 & - \\
\hline
\end{tabular}

8 trials were selected at random to be incubated for a further 24 hours. The mean absorbance of B. subtilis was less when incubated with silk (mean absorbance with silk $=0.54$, without silk $=0.56$ ) but the difference was not significant (paired samples t-test $P=0.36$ ). 4 trials showed less bacterial growth in the presence of silk and 4 showed more growth (sign test $P=1$ ).

25 paired trials were carried out to test the effect of Tegenaria silk on E. coli growth (Table 2). 15 of these trials showed lower growth in the presence of silk, 7 showed more growth and 3 showed equal growth, but the difference between silk and control samples was not significant (mean absorbance: $E$. coli alone $=0.86, E$. coli plus silk $=0.88$, sign test $+15,-7 P=0.07$, t-test $P=0.8$ ). Of the 8 trials selected at random to be incubated for a further 24 hours, 5 showed less growth in the presence of silk but the difference remained non-significant (sign test $P=0.36$, t-test $P=0.81$ ).

Silk treatment with ultraviolet light, soaking in water and Proteinase $\mathrm{K}$ and incubation with mammalian cells

5 paired trials carried out using silk exposed to ultraviolet light (Table 3) showed that the silk still appeared to retain antimicrobial activity against $B$. subtilis (mean absorbance for $\operatorname{control}=0.51$, with silk $=0.48$, sign test $P=0.03$, paired samples t-test $\mathrm{t}=3.59, P=0.016$ ).

Table 5 Table of absorbance readings of growth of B. subtilis when exposed to the Proteinase-K soaked silk of $T$. domestica

\begin{tabular}{lllcc}
\hline Trial No. & $\begin{array}{l}\text { Control } \\
\text { absorbance } \\
\text { reading }\end{array}$ & $\begin{array}{l}\text { Silk sample } \\
\text { reading }\end{array}$ & Inhibition \% & Sign test \\
\hline 1 & 0.49 & 0.50 & -2.04 & - \\
2 & 0.50 & 1.29 & -158.00 & - \\
3 & 0.55 & 0.51 & 7.27 & + \\
4 & 1.16 & 1.20 & -3.45 & - \\
\hline
\end{tabular}


In contrast, silk that had been soaked in water or incubated with Proteinase $\mathrm{K}$ no longer appeared to have any antimicrobial activity (Tables 4, 5). In tests using silk that had been soaked in water only 3 out of 7 trials showed less growth in the presence of silk (mean absorbance for B. subtilis alone $=0.61$, for $B$. subtilis plus water-soaked silk $=0.68$ ). In tests using silk that had been soaked in Proteinase K only 1 out of 4 trials showed less growth in the presence of silk (mean absorbance for B. subtilis alone $=0.67$, for $B$. subtilis plus Proteinase K-soaked silk =0.76).

4 paired trials were carried out incubating UV treated spider silk with mammalian Jurkat cels (Table 6). Treatment with UV had already been shown not to remove antimicrobial activity and was performed in this case to reduce/eliminate bacteria that were naturally contaminating the silk and whose growth might influence growth of mammalian cells. Two trials had greater numbers of cells in the control and two had greater numbers in the sample containing silk but there was no significant difference between the control and silk-containing samples (mean cell count of control $=0.67$, mean cell count of silk samples $=$ 0.67). There was no evidence to suggest that the presence of silk alters the $\mathrm{pH}$ of the in vitro cell culture or Luria broth media or sterile distilled water (zero difference between samples with and without silk was detected 24 hours and 1 week after the start of incubation).

\section{Discussion}

Natural materials have historically been a source of novel antimicrobial agents. It is estimated that from the mid1980s to the mid-1990s $78 \%$ of new drugs came from biological sources such as soil [7]. In this study we demonstrate that silk from the common house spider, $T$. domestica, appears to reduce the growth of B. subtilis under laboratory conditions. The effect appears to decrease over time with the significant effect detected at 24 but not 48 hours after the start of the experiment. A possible explanation for the apparent reduced activity with time is that the active agent is bacteriostatic in action, slowing the growth of the bacteria rather than killing them. Bacteriostatic modes of activity against $B$. subtilis are already documented in the literature [8-10] and it is conceivable that the active agent in silk also operates in this manner.

Our study of $T$. domestica silk shows that the antimicrobial activity against $B$. subtilis is reduced or negated after digestion with Proteinase $K$. The reduction of antimicrobial properties after treatment with Proteinase $\mathrm{K}$ indicates that at least one protein may be involved. Spider silk is known to be coated in glycoproteins [11] approximately $150-250 \mathrm{~nm}$ thick. It is possible the antimicrobial property of the spider silk comes from these glycoproteins. Exposure to ultraviolet light, which is expected to damage the DNA of microorganisms [12] appeared not to eliminate the activity. A non-spider origin of the antibacterial agent, such as secretion of proteins toxic to B. subtilis by bacteria already present on the silk, thus also appears unlikely to fully explain the inhibition of $B$. subtilis growth.

A similar (but non-significant) trend of reduced E. coli growth in the presence of Tegenaria silk was also observed. This may reflect the fact that our experimental set up was not sensitive enough to detect activity against this microbe or it could reflect real differences between activity against the two types of bacteria, a characteristic common to many other antimicrobial agents, which may have narrow spectra of activity [13-15]. In this context it is interesting to note that B. subtilis, unlike E. coli, is a soil bacterium [16]. We cannot completely exclude the possibility that activity against $E$. coli remains undetected in our experiment but we note that silk regularly comes into contact with soil and is much more likely to encounter B. subtilis than E. coli and thus have evolved resistance to it. It should be noted however that only two species of bacteria were tested in this experiment and thus predictions about the effect of spider silk on other species of gram positive or negative bacteria cannot be inferred from the data we have gathered.

Our initial tests of the response of mammalian cell lines cultured in vitro to Tegenaria silk indicate that the silk itself and any associated protein or chemical agents are not toxic, potentially paving the way for therapeutic applications. Modern uses of spider silk already involve using silk from spiders such as Nephila clavipes to help in mammalian neuronal regeneration [17]. Nephila silk in this case did not appear to provoke an auto immune

Table 6 Table of Jurkat cell counts per $\mathrm{ml}$ and $\mathrm{pH}$ when exposed to silk of $T$. domestica

\begin{tabular}{lllllll}
\hline Trial No. & $\begin{array}{l}\text { Number of million } \\
\text { control cells per } \mathbf{m l}\end{array}$ & $\begin{array}{l}\text { Number of million } \\
\text { silk cells per } \mathbf{m l}\end{array}$ & Control pH 1 day & Silk pH 1 day & Control pH 1 week & Silk pH 1 week \\
\hline 1 & 1.12 & 1.08 & 6.4 & 7 & 7.4 \\
2 & 0.72 & 0.54 & 6.7 & 6.7 & 6.7 \\
3 & 0.44 & 0.52 & 7.2 & 6.7 & 7.2 \\
4 & 0.4 & 0.54 & 7.2 & 7.2 & 7.2 & 7.2 \\
\hline
\end{tabular}


response. This is an important factor to consider because if a material is to be used therapeutically then it is important that the material is neither toxic nor swiftly destroyed by the recipient's immune system.

Other recent biotechnological applications of spider silk includes the use of recombinant spider silk particles as drug delivery vehicles [18]. Spider silk has also been suggested to be used as a load bearing biomaterial by Brown [19] because of its biocompatibility, and strength and toughness. Other potential uses have been proposed with applications ranging from artificial tendons [20] to rust free panels having been suggested [21]. Spider silk has been suggested as a suitable replacement material for many existing products such as clothing, ropes, seat belts, body armour, parachutes and biodegradable bottles, all of which could show both cost and environmental benefits if made from spider silk rather than current manmade materials [21]. We suggest that an added benefit to these sorts of applied uses is the potential for the products to have a level of intrinsic antimicrobial activity.

Our experiment demonstrates that an antimicrobial effect exists in silk in its native form, a property that may have evolved in order that silk can resist microbial decomposition. Reduced decomposition might be advantageous if it decreases the energetic costs of web maintenance and/or the level of harmful microbes to which a spider is exposed. The effect might be even more strongly selected for in silks that protect developing eggs, which might be particularly adapted to resist decomposition or destruction by predators, parasites or fluctuations in external abiotic conditions [22]. Reducing the bacteria present on the silk could also make the web harder to detect by prey by visual or olfactory signals. In addition it has been observed that the presence of aciniform silk leads to a delay in prey decomposition [23] reducing the exposure to microbes and increasing the amount of substance ingested. It remains to be seen whether antimicrobial activity is observed in other silks from a wider range of species and if so, whether the traits are homologous or have evolved independently as a response to similar microbial challenges in their environment.

\section{Competing interests}

The authors declare that they have no competing interests.

\section{Authors' contributions}

SW conceived of the study, carried out the data collection and analysis and drafted the manuscript. SLG participated in the design of the study and helped draft the manuscript. Both authors read and approved the final manuscript.

\section{Authors' information}

SLG is a RCUK Academic Fellow, in the Faculty of Medicine \& Health Sciences at the University of Nottingham and runs the 'SpiderLab' at Nottingham, working on a range of evolutionary, population and conservation genetic studies using spiders as model systems. SW at the time of the research was a
Masters of Research student at the University of Nottingham supervised by SLG.

\section{Acknowledgements}

The Authors thank Kelly-Ann Vere, Senior Technician in the Faculty of Medicine \& Health Sciences, University of Nottingham for assisting with the mammal cell experiments. We also thank all members of staff at The School of Biology at The University of Nottingham who assisted with this study.

Received: 21 February 2012 Accepted: 1 June 2012

Published: 25 June 2012

\section{References}

1. Vollrath F, Knight DP: Liquid crystalline spinning of spider silk. Nature 2001, 410(6828):541-548.

2. Swanson BO, Blackledge TA, Hayashi CY: Spider capture silk: performance implications of variation in an exceptional biomaterial. Journal of Experimental Zoology Part A: Ecological Genetics and Physiology 2007, 307(11):654-666.

3. Blackledge TA, Hayashi CY: Silken toolkits: biomechanics of silk fibers spun by the orb web spider Argiope argentata (Fabricius 1775). Journal of Experimental Biology 2006, 209(13):2452-2461.

4. Roberts MJ, Spiders of Britain and northern Europe: Collins field guide Collins: London; 1995:383p. 32 col. plates.

5. Sahni V, Blackledge TA, Dhinojwala A: Viscoelastic solids explain spider web stickiness. Nature Communications 2010, 1(2):1-4.

6. Heimer S: Wunderbare Welt der Spinnen.; 1988. Urania Verlag Leipzig Jena Berlin

7. Cragg GM, Newman DJ, Snader KM: Natural products in drug discovery and development. Journal of natural products 1997, 60(1):52-60.

8. Kubo I, et al: Antibacterial activity of akyl gallates against Bacillus subtilis. Journal of Agricultural and Food Chemistry 2004, 52(5):1072-1076.

9. Ogilvie A, Wiebauer K, Kersten W: Inhibition of leucyl-transfer ribonucleic acid synthetase in Bacillus subtilis by granaticin. Biochem. J 1975, 152:511-515.

10. Bonvehí J, Coll F, Jordà R: The composition, active components and bacteriostatic activity of propolis in dietetics. Journal of the American Oil Chemists' Society 1994, 71(5):529-532.

11. Augsten K, Muehlig P, Herrmann C: Glycoproteins and skin core structure in Nephila clavipes spider silk observed by light and electron microscopy. Scanning 2000, 22(1):12-15.

12. Novick A, Szilard L: Experiments on light-reactivation of ultra-violet inactivated bacteria. Proceedings of the National Academy of Sciences of the United States of America 1949, 35(10):591.

13. Yamamoto $K$, et al: Antibacterial agents that inhibit histidine protein kinase YycG of Bacillus subtilis. Bioscience, Biotechnology, and Biochemistry 2001, 65(10):2306-2310.

14. Lai J, et al: Design of Non-Cysteine-Containing Antimicrobial -Hairpins: Structure- Activity Relationship Studies with Linear Protegrin-1 Analogues. Biochemistry 2002, 41(42):12835-12842.

15. Perry N, Blunt J, Munro M: A cytotoxic and antifungal 1, 4-naphthoquinone and related compounds from a New Zealand brown alga, Landsburgia quercifolia. Journal of Natural Products 1991, 54(4):978-985.

16. Henschke R, Schmidt F: Survival, distribution, and gene transfer of bacteria in a compact soil microcosm system. Biology and Fertility of Soils 1989, 8(1):19-24.

17. Allmeling C, et al: Use of spider silk fibres as an innovative material in a biocompatible artificial nerve conduit. Journal of Cellular and Molecular Medicine 2006, 10(3):770-777.

18. Lammel A, et al: Recombinant spider silk particles as drug delivery vehicles. Biomaterials 2011, 32:2233-2240.

19. Brown CP RF, Traversa E, Licoccia S: Spider silk as a load bearing biomaterial: tailoring mechanical properties via structural modifications. Nanoscale Materials and Modeling-Relations among Processing, Microstructure and Mechanical Properties; 2011.

20. Kaplan DL: Wiley Online Library. 1996.

21. Gole RS, Kumar P, Spider's silk: Investigation of spinning process, web material and its properties. Available from http://www.iitk.ac.in/bsbe/web\%20on\% 20asmi/spider.pdf. 
22. Zhao $\mathrm{AC}$, et al: Unique molecular architecture of egg case silk protein in a spider, Nephila clavata. Journal of Biochemistry 2005, 138(5):593-604.

23. Zortea ADA, Fischer ML: Discard of preys and silk antimicrobial activity in the Loxosceles intermedia Mello-leitao, 1934 and Loxosceles laeta (Nicolet, 1849) (Araneae; Sicariidae). Revista Brasileira de Zoociencias 2009, 11(1):47-53.

doi:10.1186/1756-0500-5-326

Cite this article as: Wright and Goodacre: Evidence for antimicrobial activity associated with common house spider silk. BMC Research Notes 2012 5:326.

\section{Submit your next manuscript to BioMed Central} and take full advantage of:

- Convenient online submission

- Thorough peer review

- No space constraints or color figure charges

- Immediate publication on acceptance

- Inclusion in PubMed, CAS, Scopus and Google Scholar

- Research which is freely available for redistribution 